\title{
Article \\ Failure Analysis of Steel Fiber-Reinforced Concrete T-Beams without Shear Stirrups
}

\author{
Inkyu Rhee
}

Department of Civil Engineering, Chonnam National University, Gwangju 61186, Korea; rheei@jnu.ac.kr

\begin{abstract}
The shear failure of a reinforced concrete member is a sudden diagonal tension failure; flexible failure is gradual, associated with significant cracks, and leads to extensive sagging. Therefore, reinforced shear rebars are commonly used to ensure that flexible failure occurs before shear failure under extreme conditions. Extensive efforts are underway to replace conventional shear reinforcements with steel fibers. Here, a nonlinear analysis of a steel fiber-reinforced concrete T-beam was performed in order to estimate the maximum shear capacity with the aid of experimental test data. A continuum-damaged plasticity model and modified compression field theory were used for nonlinear analysis. Three $360 \times 360$-mm web elements were selected between the shear span; changes in the principal axis caused by crack development and propagation were traced. Changes in the crack angle according to the average strain of the bottom longitudinal reinforcement and the vertical strain of the web element were also determined. For verification, a strut-tie model was used to predict shear capacity. The experimental results and the finite element analyses were in good agreement.
\end{abstract}

Keywords: SFRC; shear capacity; concrete damaged plasticity; modified compression field theory

check for

updates

Citation: Rhee, I. Failure Analysis of Steel Fiber-Reinforced Concrete T-Beams without Shear Stirrups. Appl. Sci. 2022, 12, 411. https://doi.org/ 10.3390/app12010411

Academic Editor: Doo-Yeol Yoo

Received: 24 November 2021

Accepted: 30 December 2021

Published: 1 January 2022

Publisher's Note: MDPI stays neutral with regard to jurisdictional claims in published maps and institutional affiliations.

Copyright: (c) 2022 by the author. Licensee MDPI, Basel, Switzerland. This article is an open access article distributed under the terms and conditions of the Creative Commons Attribution (CC BY) license (https:// creativecommons.org/licenses/by/ $4.0 /)$.

\section{Introduction}

Shear stirrups are commonly used to ensure that flexible failure occurs before shear failure under extreme conditions. Such reinforced concrete structures exhibit various forms of shear-related failure. It is difficult to accurately predict shear failure. Despite many experiments [1-3] and interpretations [4-8] over the years, shear failure remains poorly understood; the design of shear force-bearing members continues to rely on formulae derived from experimental data.

The behavior after diagonal tension cracking fundamentally differs from flexural behavior after flexural cracking. Such cracking is acceptable on the tensile side of the member that receives the bending moment; the cracks do not affect member flexural strength. However, member flexural strength is influenced by diagonal tension cracking, which is caused principally by shear stress. In general, if only flexural tensile bars are placed (i.e., no other rebar is present), a diagonal tension crack will seriously compromise member behavior and strength.

Many shear experiments [1-3] have shown that a single diagonal tension crack in a member web immediately extends across the entire depth of the member; the member separates into two pieces and thus fails. If rebar is not appropriately placed on the member web, an unexpected overload may result in instantaneous collapse. Thus, regardless of whether web rebar is not computationally necessary, minimum shear rebar should always be placed. This offers a visible warning before member collapse; it ensures ductility by inhibiting diagonal tension crack growth. Reinforcing steel fibers (SFs) may also ensure ductility where shear stresses dominate. The shear force when the web experiences a diagonal tension crack is the maximum force that the member can resist (i.e., the member shear strength); this is usually the concrete shear strength. For many reasons (in addition to low cost), both the reinforcements and the member itself should exhibit high-level flexural resistance. In addition, the member must not fail instantaneously/explosively 
(shear failure) in extremis; it should fail in a manner wherein the ductility allows gradual failure [9-15].

Previous analyses [1-3] showed that the $45^{\circ}$ truss model (an ACI shear strength predictor) exhibited a 1.4-fold difference between the experimental and predicted data. To improve this difference, the MCFT model was developed in the 1980s to manage the entire load-displacement curve. The accuracy of this model improved the experimental-predictive ratio to 1.01 [4]. However, the computation was complex; a simplified MCFT method was proposed by Bentz et al. [8]. Simplification of shear strength prediction was important in practical terms; Mihaylov et al. [16-20] thus developed a two-parameter kinematic theory. A predictive equation comprehensively calculated crack width, maximum sagging, and the overall load-displacement relationship. The two kinematic degrees of freedom were the vertical displacement under the loading platen and averaged longitudinal strain of bottom reinforcement. These reflected the total shear force balance calculated using the internal moment balance and the tensile force (including the tensile reinforcement effect imparted by the bottom reinforcement and the surrounding concrete). Previously, moment balance required repetitive calculations. Thus, the predictive formula established by Mihaylov et al. [21-23] was expanded by calculating the shear resistance in the direction of the SFs. The deformation softening behavior, the SF shape, and the sine field crack of the FRC beam were all considered (Tvrznikova [19], Robet [20]). The tensile behaviors of steel fiber-reinforced concrete (SFRC) were derived by Mansur et al. [24] and Lee et al. $[25,26]$ at various compressive strengths; the simplified diverse embedment model method established by Lee et al. [25] is simple and generally accurate.

This paper intends to perform a nonlinear analysis that numerically confirms the maximum shear strength of the SFRC T-beam without shear stirrup. Among the theories on various shear failures, the average behavior of web elements in the shear span (inclined cracking in terms of transverse strain, and longitudinal strain) was examined, and the change in the crack angle until major failure was traced. In order to do this, three web elements were selected. The inter-relationship among the deformation of web elements, the average longitudinal strain of the bottom rebar, and the crack angle was measured by using Mohr circle. To verify these results, the strut-tie model was used.

\section{Shear Critical Failure Test of an R/FRC T-Beam}

Barros et al. [27] compared experimental results with the data of a blind analysis competition featuring three-point loading of concrete beams reinforced with short steel fibers. Blind analysis using the flexural performance and material constants of SFRC (disclosed in advance) predicted the maximum shear strength and strain of the lower rebar of the load action point using various models (smeared crack, discrete crack, and continuum-damage). The compressive strength of SFRC used in both the experiments and the analyses was $67 \mathrm{MPa}$, the water-cement ratio was 0.4 , and the SF per unit volume was $60 \mathrm{~kg}$. The volume fraction of steel fiber was $0.76 \%$. Residual flexural stresses were provided in advance via SFRC three-point bending tests. The T-shaped beam in that work has the cross-section and specifications as shown in Figure 1a. The shear critical span ratio (a/d) was approximately 3.0 (2.955) and the beam was slender. The bottom reinforcement was three singly arranged $\$ 25$ rebar; the left side of the asymmetric three-point loading area without shear reinforcement. It is important to explore whether SFs can be used to resist shear in the absence of conventional reinforcement. SFs are presumed to enhance strength and ductility (despite sagging), while increasing resistance to extreme loads. An SF draws on the surface near a shear crack; the direction of drawing is thus important. Shear transfer strength via aggregate interlocking greatly contributes to the total shear resistance. As shown in Figure 1b, the beam finally underwent shear failure. Three inclined cracks developed and expanded at speeds proportional to the loads, such that longitudinal cracks occurred along the bottom rebar; a large, inclined crack then developed in the middle and destroyed the beam. Mihaylov et al. (2013) found that the shear crack angle depended on the shear-span-to-depth (a/d) ratio; it was smaller between $\alpha$ and $\theta$, where $\alpha$ is the angle of 
the shortest distance between the inner points of the support platen, and the loading point and $\theta$ is the angle of the inclined crack (Figure 1b). The angles of the three major inclined cracks increased with the level of loading (1) $\rightarrow$ (2) $\rightarrow$ (3) $\rightarrow$ (4)); $\theta_{1}, \theta_{2}$, and $\theta_{3}$ were $32^{\circ}, 35^{\circ}$, and $50^{\circ}$ (by inspection); $\alpha$ was $21^{\circ}$. The shear crack angle thus depends on the minimum angle (here, $21^{\circ}$ ).
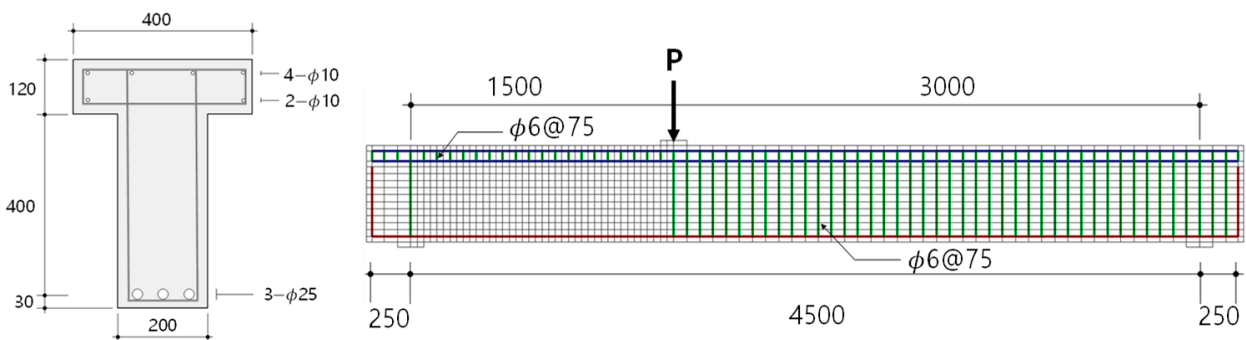

(a)

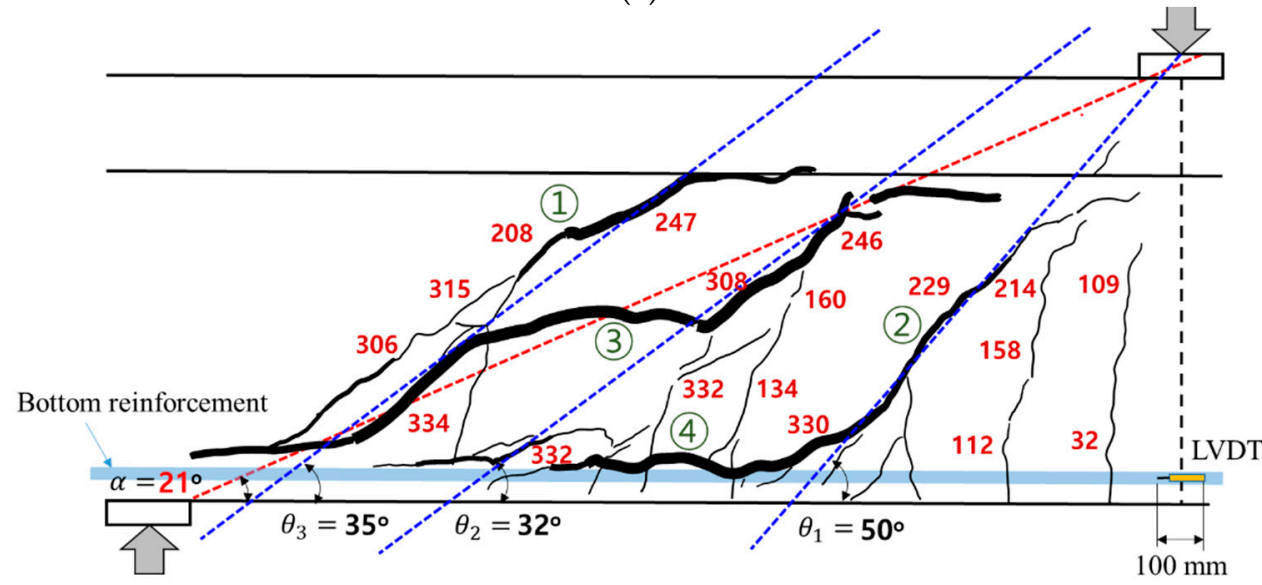

(b)

Figure 1. Specimen layout and crack pattern. (a) Cross-section, geometry, and reinforcements of the SFRC beam. (b) Failure pattern of the SFRC T-beam during the three-point bending test $(\mathrm{kN})$.

Because the angle of inclination rotates under different loading/unloading conditions, the angle was developed vertically (under flexure); it was then extended and rotated toward both the loading point and the support. Figure 2 illustrates the shear force V and its relationship with the inclined angle $\theta$; this relationship is affected by the nature of web reinforcement.

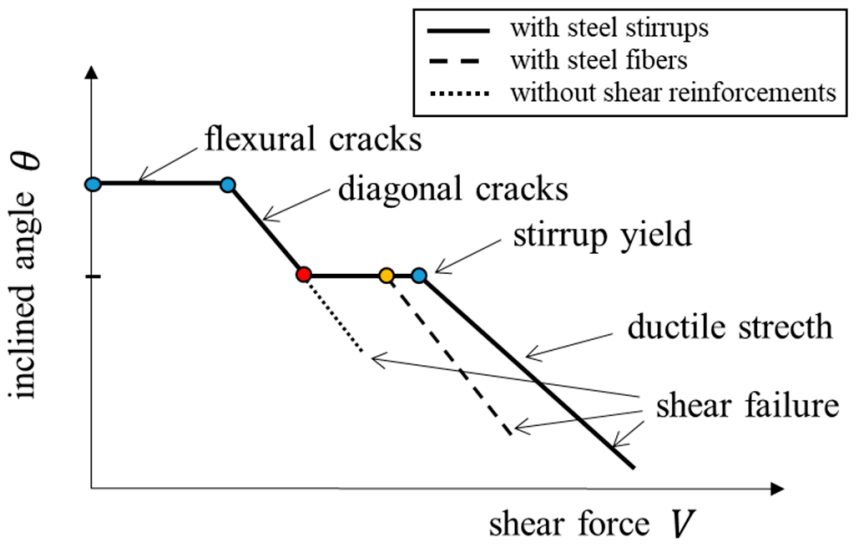

Figure 2. Variation in the angle of inclination of a web-shear crack according to the chosen web reinforcement, against the shear force. 
The angle of inclination of the web strut varied with the applied loading (Figure 3). During early loading, when the web-induced diagonal tensile stress attained the concrete tensile strength, a diagonal crack commenced; as the shear force increased, cracks gradually spread, eventually reducing the strain inclination angle of the strut (after some oscillating variations). The web fibers yielded when the shear force increased further; the diagonal crack was then stabilized. The longitudinal, transverse, and compressive strut strains in a web element are shown in Figure 3a. The transverse strain $\varepsilon_{t}$ increases when the angle of inclination is reduced, as shown by the Mohr circle of Figure $3 b$.

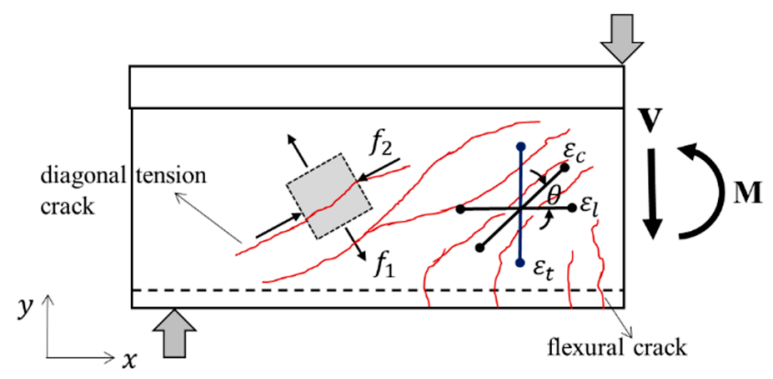

(a)

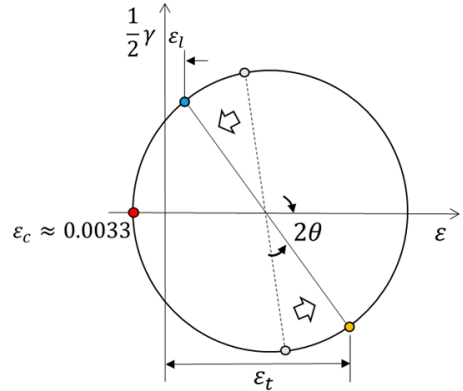

(b)

Figure 3. Strains in the web element. (a) Longitudinal, transverse, and compressive strut strains. (b) The transverse strain increased when the angle of inclination was reduced (Mohr circle).

\section{Finite Element Models}

Two principal, constitutive, SFRC finite element models were used for nonlinear analysis; the first analysis was conducted using the continuum-damaged plasticity model of ABAQUS [28]. The compressive strength, initial elastic modulus, and Poisson's ratio were set to $f_{c}^{\prime}=67.1 \mathrm{MPa}, E_{c i}=21,500\left[f_{c m} / 10\right]^{1 / 3}=40,552 \mathrm{MPa}$, and $v=0.2$, respectively. A nonlinear material model to consider material damage in both compression and tension was used. The dilation angle, eccentricity, the ratio of the equi-biaxial compressive yield stress to the uniaxial initial yield stress, and the ratio of the second stress invariants on the tensile meridian to the second stress invariants on the compressive meridian were $52^{\circ}$, $0.1,1.16$, and $2 / 3$, respectively. The damaged plasticity model for concrete in ABAQUS is based on the models proposed by Lubliner et al. [29] and by Lee and Fenves [30]. The Modified Drucker-Prager yield criterion is used with consideration of Lubliner Model (Lubliner, 1989) and damaged plasticity model (Lee and Fenves, 1998) for concrete and other quasi-brittle materials. This concrete damaged plasticity model has been widely used for RC and FRC application in both static and dynamic situation [31-34]. The volume fraction of SF was set to $0.76 \%\left(l_{f}=33 \mathrm{~mm}, d_{f}=0.55 \mathrm{~mm}\right)$. A linear-hardening model to manage the rebar and stirrups was used. The yield and ultimate strengths of the rebars and stirrups in compression/tension were 538/696 for $10 \mathrm{~mm}$ rebar, 557/678 for $25 \mathrm{~mm}$ rebar, and $527 / 700 \mathrm{MPa}$ for $6 \mathrm{~mm}$ stirrups, respectively. The elastic modulus of the rebar/stirrups was $E_{S}=210 \mathrm{GPa} ; v$ was 0.3 when employing a three-dimensional (3D) continuum element for concrete and a 3D truss element for the rebars. When running ABAQUS, 9910 elements (T3D) were used for rebars, and 3432 (C3D20) and 90,321 (C3D8) elements were used for the SFRC T-beam. Nonlinear steel was assumed to be perfectly plastic. Figure $4 \mathrm{a}, \mathrm{b}$ show the compressive and tensile strength of SFRC in terms of the inelastic strain. To build a tension-stiffening model of SFRC, Figure 4c was calibrated using the Load-CMOD data of a flexural tensile test (Barros et al. [27]). 


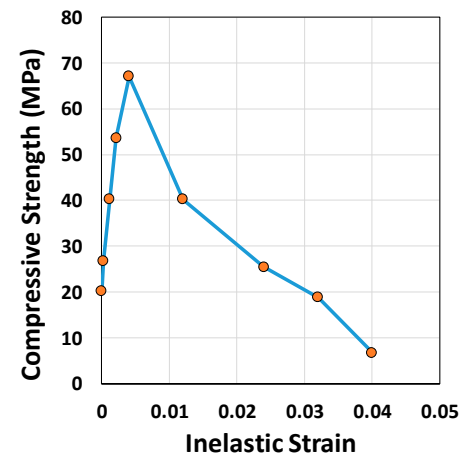

(a)

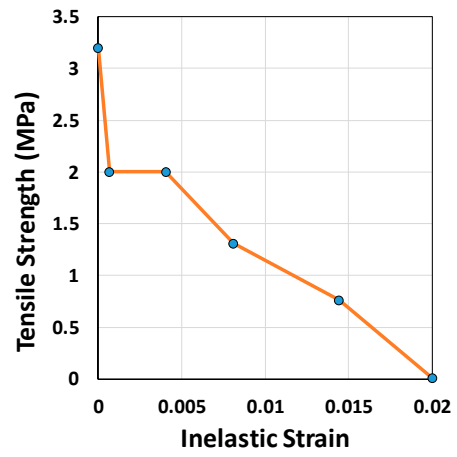

(b)

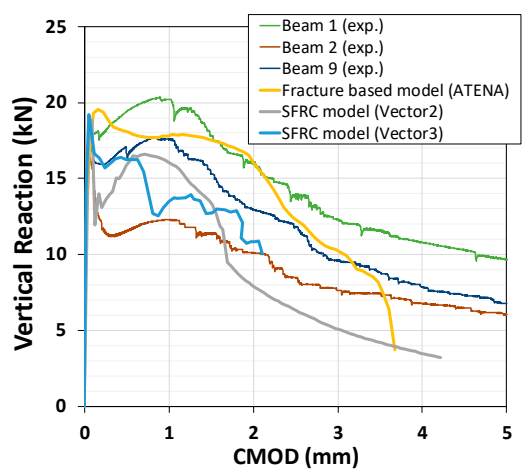

(c)

Figure 4. Compression and tension behaviors of SFRC. (a) Compressive softening. (b) Tension softening. (c) The P-CMOD for a single-notched SFRC beam.

In the 2D models, 829 truss elements for the rebars and 1240 rectangular elements for the SFRC T-beam were used when running the Vector2 [35], Modified Kent-Park, and Vecchio (1992) models. A Hognestad parabola was used to examine compression post-peak behavior and softening. A modified Bentz model (2003) and a nonlinear Hordijk model were employed to manage tension stiffening and softening, respectively. The simplified diverse embedment model (2013) was combined with the post-crack FRC tension model. The Eligehausen model [36] was used to manage concrete bonding. The Distributed Stress Field model combined with modified compression field theory (MCFT, [4]) was employed to calculate crack stress (Figure 5).
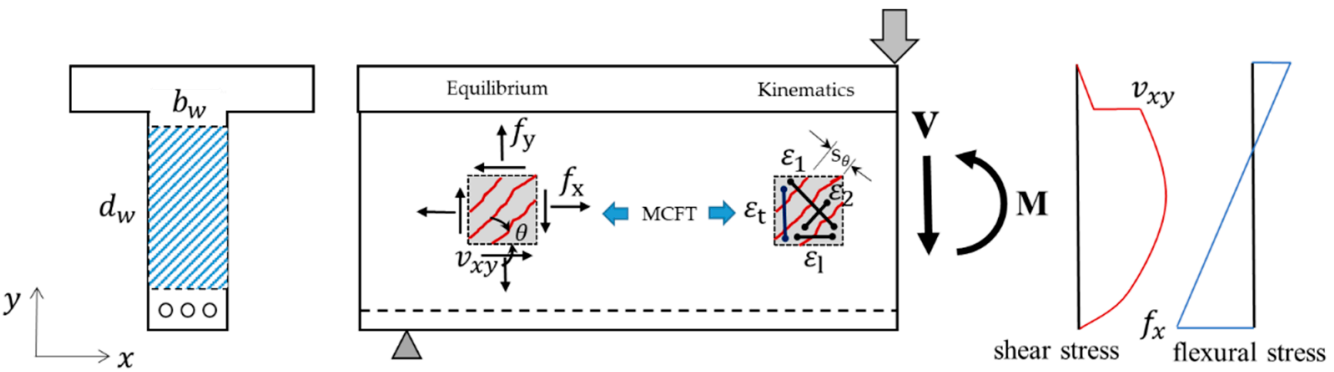

Figure 5. MCFT: Fiber-induced stress at a cracked surface and the associated shear force.

\section{Results and Discussions}

The vertical displacement at the loading point was controlled up to $25 \mathrm{~mm}$. The corresponding vertical reactions were monitored during simulations. Figure 6a shows cracking at loading stages $0.1,0.2,0.5$, and 1.0. At stages 0.1 and 0.2 , flexural cracks were dominant and spread because of the bottom reinforcement. As loading increased, diagonal cracks developed in the shear span and spread perpendicularly to form three major shear cracks. Figure $6 \mathrm{~b}$ shows the rebar stresses in the bottom and top reinforcements and the stirrups. The maximum longitudinal stress in the bottom reinforcement was elastic as the shear cracks developed. Figure $6 c$ shows the damage to three sections of the shear span. The tensile damage was higher in the section of the loading plane; the diagonal tensile cracks were more severe than the other cracks. Figure $6 \mathrm{~d}$ shows the blunt crack patterns yielded by Vector2/MCFT analyses. These patterns were similar to patterns derived using ABAQUS (Figure 6a). 

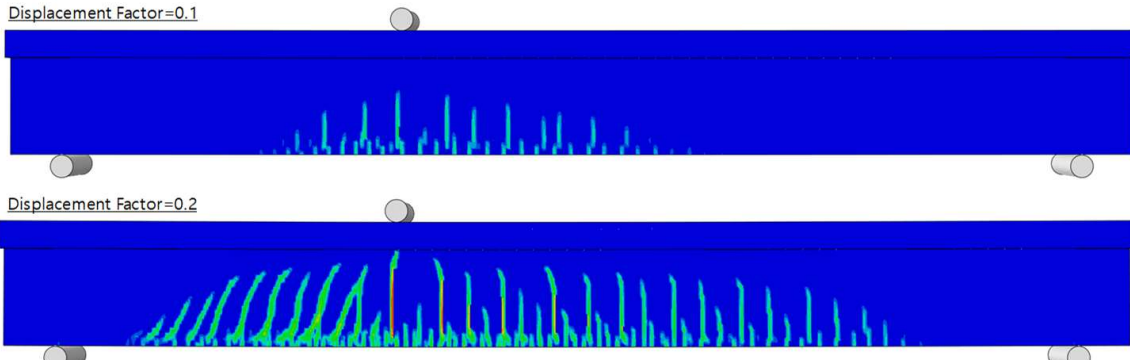

O

( )
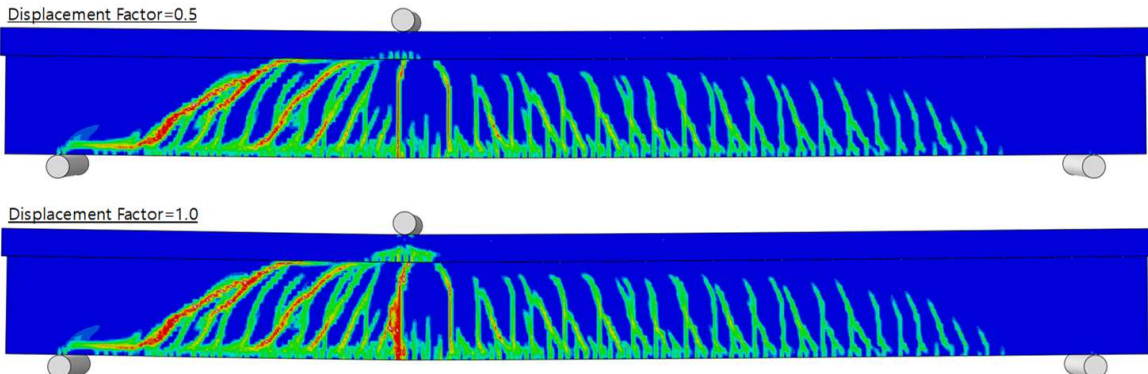

(a)

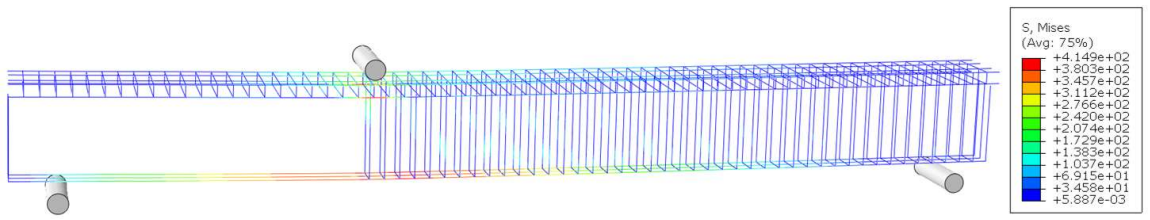

(b)

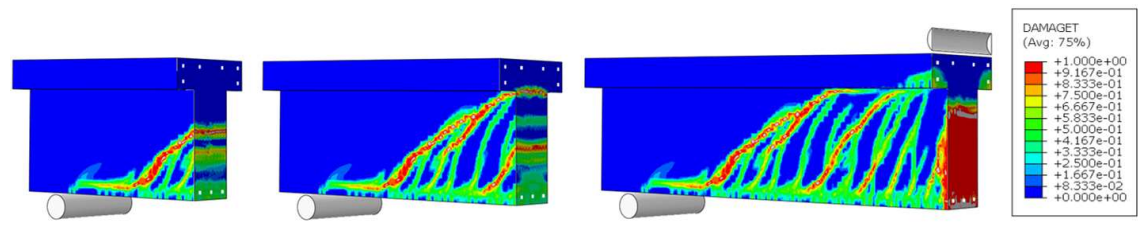

(c)

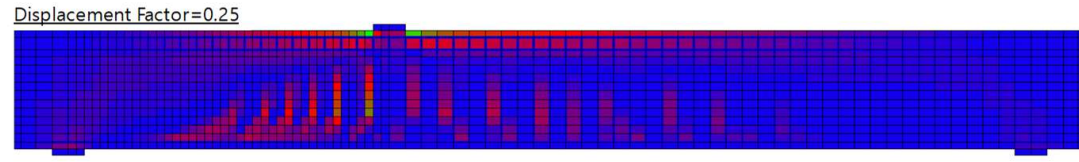

Displacement Factor $=0.36$

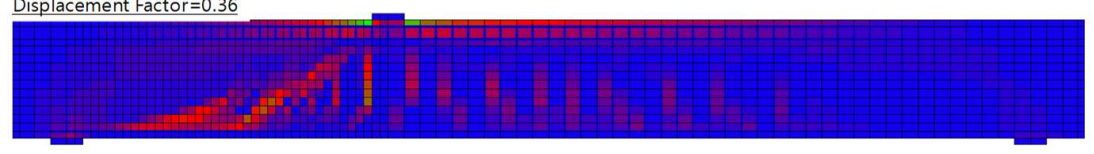

Displacement Factor $=0.53$

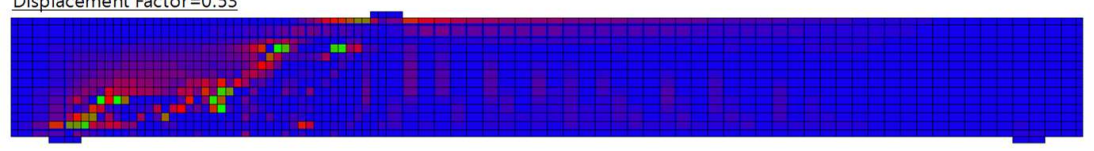

Displacement Factor $=0.86$

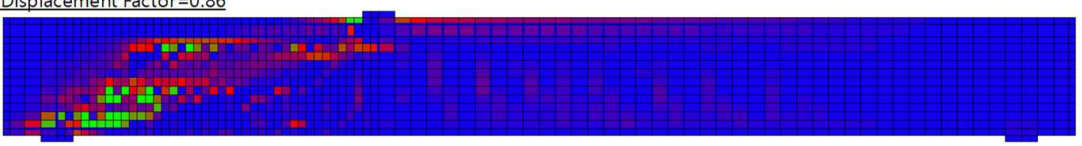

(d)

Figure 6. Failure patterns of the SFRC T-beam under the three-point bending test. (a) Crack patterns of ABAQUS. (b) von-Mises stress in the reinforcements. (c) Tensile damage. (d) Crack patterns of Vector2. 
Three windows of $360 \times 360 \mathrm{~mm}$ in the shear span: (1) flexure-dominant, (2) primary shear-critical, and (3) secondary shear-critical (Figure 7a) were selected for the sake of the modified compression field theory. Figure $7 \mathrm{~b}$ plots the deformations of all windows at a displacement factor $=0.9$ (10-fold magnification). The shear deformations of windows 2 and 3 are the deformations of web elements under bi-axial stress. Figure $7 \mathrm{c}, \mathrm{d}$ depicts migration (expansion/shrinkage) during stretching and softening. The angle of inclination of the principal axis tended to fall because the transverse strain $\varepsilon_{t}$ gradually increased as the shear cracks spread; this was followed by abrupt failure in the middle of the shear span. Figure 7e,f shows the rotations of the principal axis according to the load-induced stress variations in the web elements. Figures 8 and 9 show the changes in the inclination angle of the web-shear crack according to the web shear force reinforcement. As shown in Figure 9, the longitudinal average tensile strain $\varepsilon_{t, a v g}$ decreased while the transverse strain $\varepsilon_{t}$ gradually increased. Web elements in a biaxial stress state rotate the crack angle as the averaged tensile strain of the bottom rebar increases, and the strain is released when the SFRC beam failed abruptly. As the inclined cracks of the web elements disperse and increase, the transverse strain also increases, accelerating the rotation of the crack angle. These series of immigration processes are well represented in Figure $7 \mathrm{~d}-\mathrm{f}$ by load level in Mohr circle. In the case of Vector2/MCFT, which is based on strain, the progressive failure of web elements is well depicted in the biaxial strain relationship, as shown in Figure 7d. Conversely, Abaqus result shows better failure trace of web elements under their biaxial stress state in a stress-based Mohr circle as shown in Figure 7e. MCFT, which analyzes changes in macro web elements based on average strain and average stress, can be interpreted as more suitable for SFRC structures than relatively local nodal or element-based analysis.

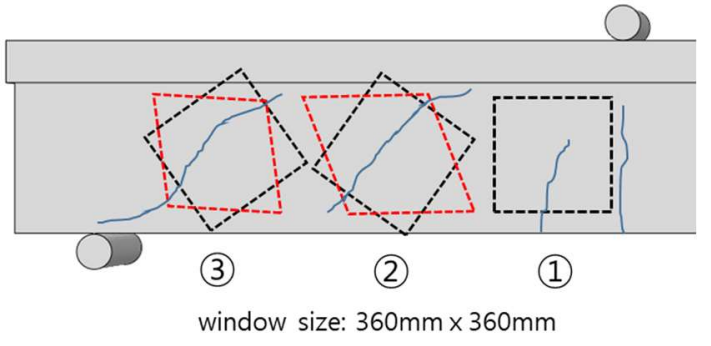

(a)

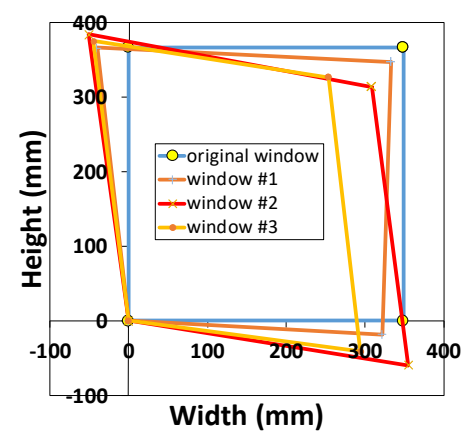

(b)
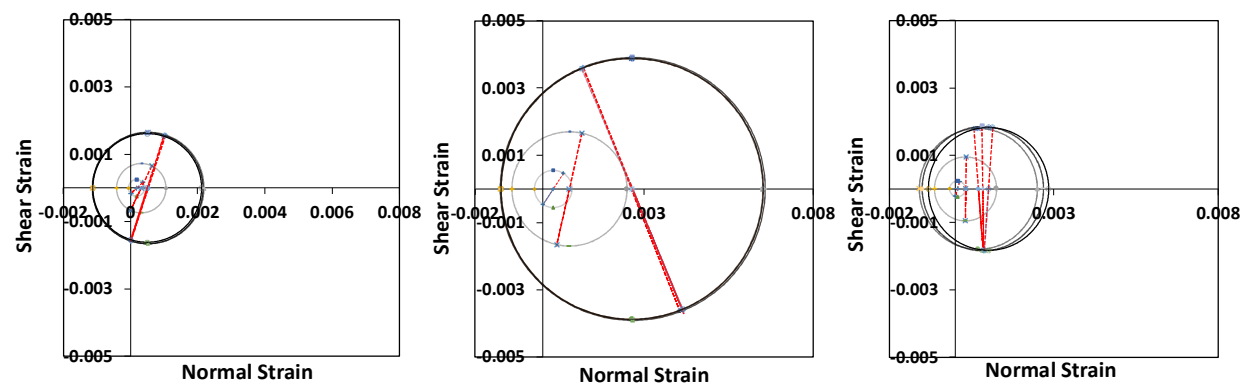

(c)

Figure 7. Cont. 

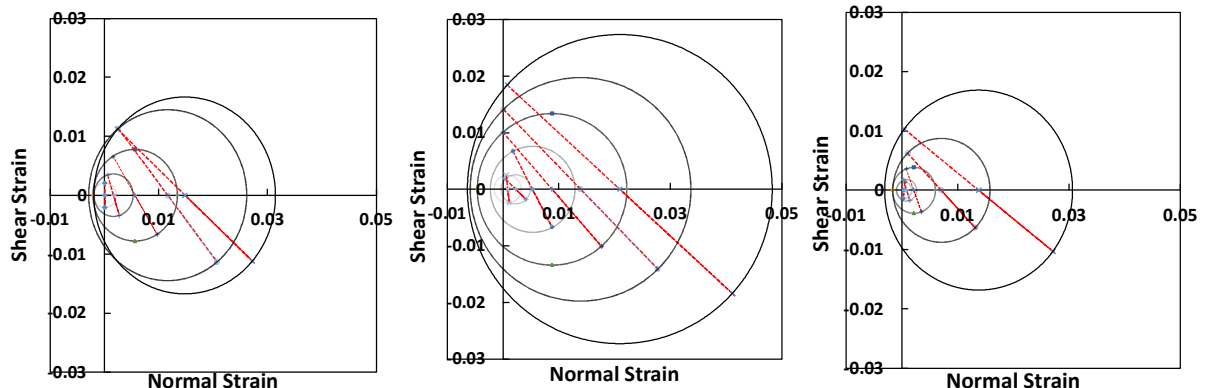

(d)

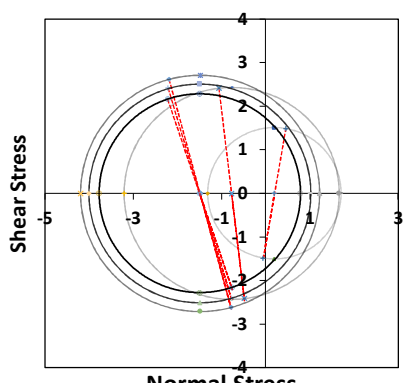

Normal Stress

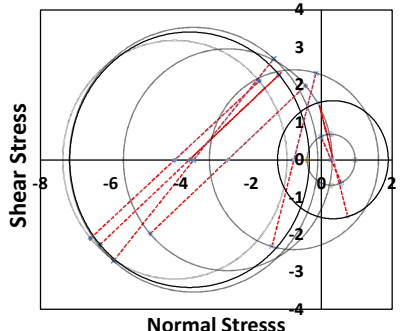

Normal Stresss

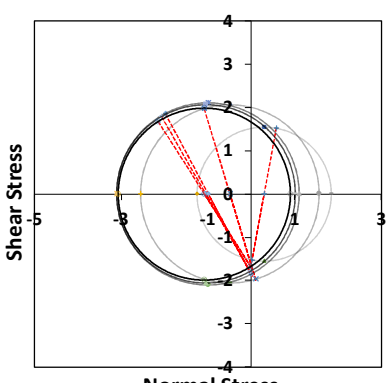

Normal Stress

(e)
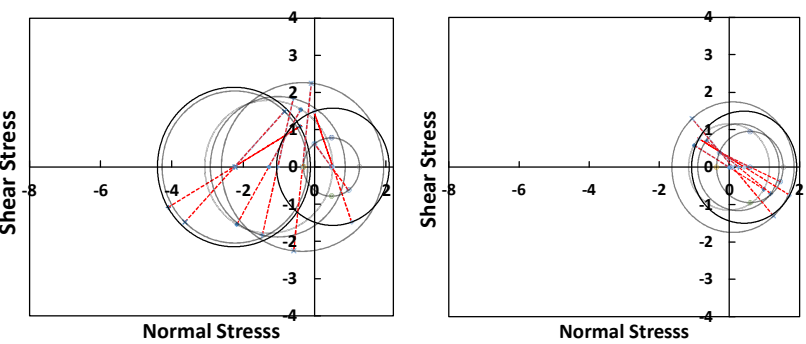

(f)

Figure 7. Variations in the angle of inclination of the web-shear crack according to the web shear force reinforcements. (a) Three windows in the web. (b) Shear distortions in web elements (10-fold magnification). Mohr's circles showing (c) the ABAQUS strain, (d) the Vector2 strain, (e) the ABAQUS stress, and (f) the Vector2 stress.

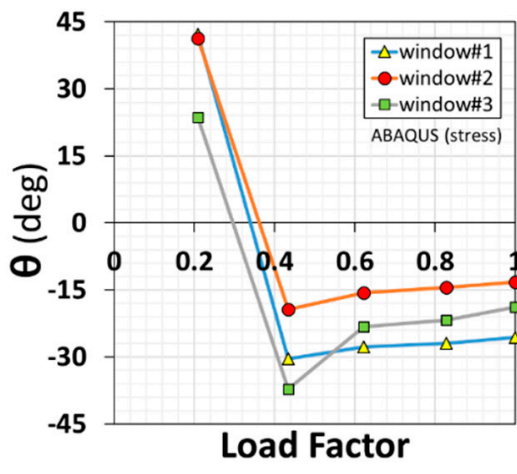

(a)

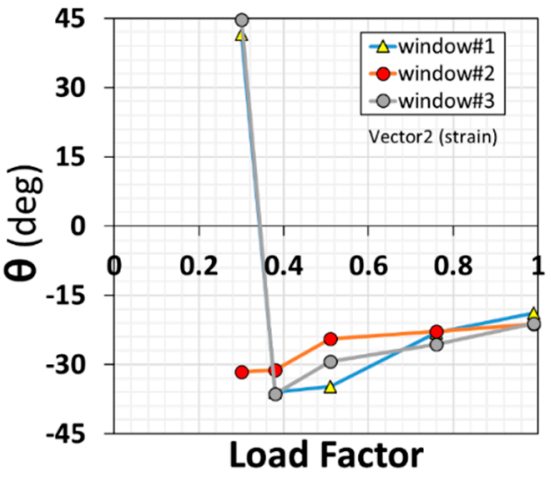

(b)

Figure 8. Variations in the angle of inclination of the web-shear crack according to the load factor. (a) ABAQUS. (b) Vector2. 


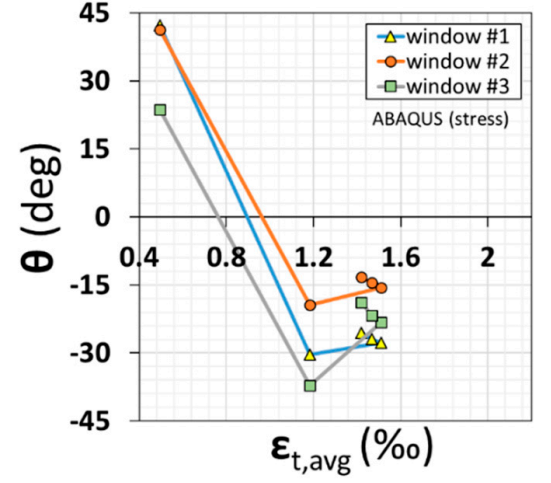

(a)

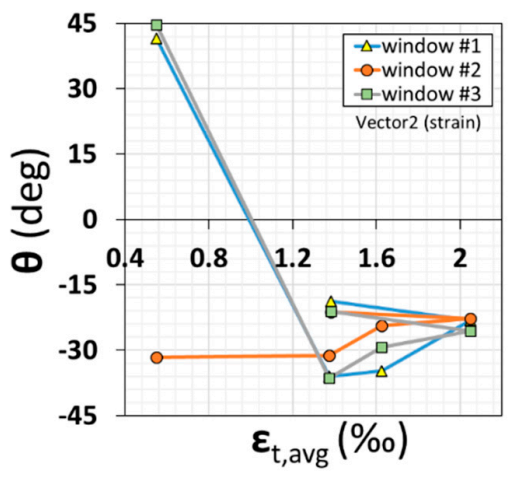

(b)

Figure 9. Variations in the angle of inclination of the web-shear crack according to the average tensile strain of the bottom reinforcement. (a) ABAQUS. (b) Vector2.

The inclination angle $\theta$ decreased continuously until approximately $21^{\circ}$ in the strain and $14-28^{\circ}$ in the stress Mohr circles. If web reinforcements were present, the compressive strain limit of concrete was attained at $\varepsilon_{\mathcal{C}}=0.0033$ (i.e., the concrete crush strain), at $\varepsilon_{l} \sim 0.001$ for the bottom reinforcement (the tensile strain) and at $\varepsilon_{t} \sim 0.0025$ for the web element (the transverse strain when the rebar is fully yielded; Figure 7). Then, the inclination angle $\theta$ decreased to approximately $21^{\circ}$ at shear failure during loading. Because we did not apply any web reinforcement, the SFs were lodged in plain concrete. The vertical (transverse) strains at various longitudinal locations were monitored as shown in Figure 10. Six locations were chosen at 0, 250, 330, 640, 940, and $1200 \mathrm{~mm}$ distant from the loading point (Figure 10a). The transverse strain increased with increasing shear strain. In the flexure-dominant monitoring line at $0 \mathrm{~mm}$, the transverse strain increased to 0.001 , whereas the transverse strains of the shear-dominant lines at 640 and $940 \mathrm{~mm}$ increased to $0.0025-0.0029$ (Figure 10b). The longitudinal strains decreased as the transverse strains increased at the shear-dominant lines (Figure 10c). Figure 10d,e shows the longitudinal and transverse strains associated with deflections under the loading points.

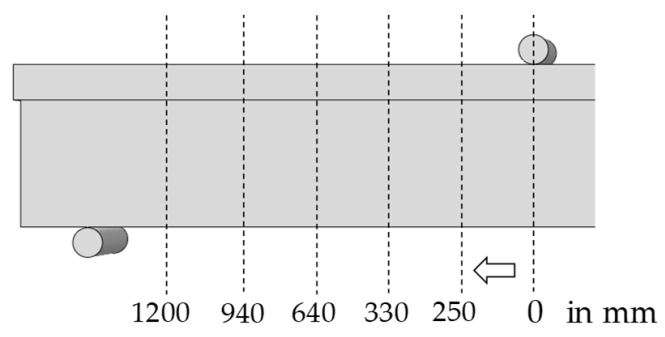

(a)

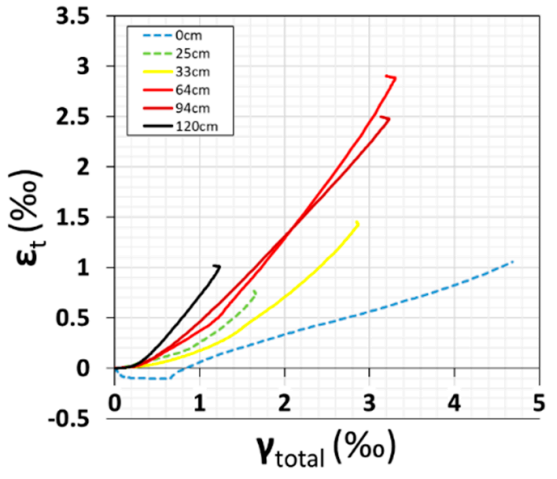

(b)

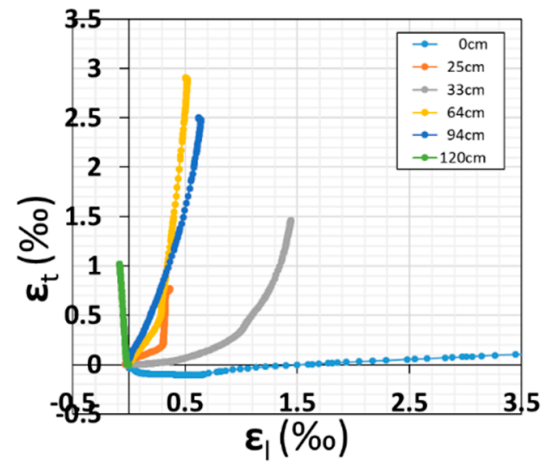

(c)

Figure 10. Cont. 


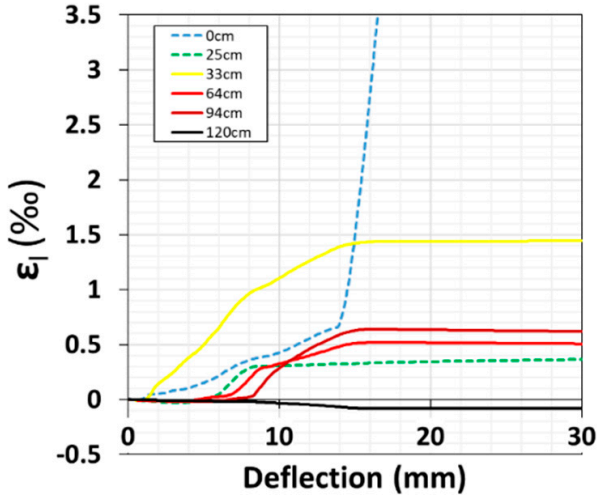

(d)

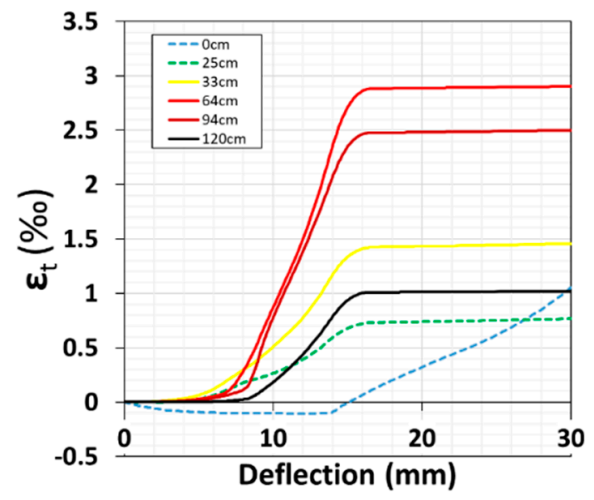

(e)

Figure 10. Strains. (a) Monitoring locations. (b) Shear strain-transverse strain plots. (c) Longitudinal strain-transverse strain plots. (d) Longitudinal strain-deflection plots. (e) Transverse strain-deflection plots.

The shear stress-strain curves at the various monitoring lines exhibited shear stress maxima of 1.4-2.1 MPa as the shear strains failed at approximately 0.003 , with the exception of the flexure-dominant line at $0 \mathrm{~mm}$ (Figure 11a). The average tensile damage was $0.1-0.26$ in shear-dominant web elements but 0.42 in the flexure-dominant element (Figure 11b). Figure $6 \mathrm{c}$ shows a graphical representation of tensile damage across the various cross-sections.

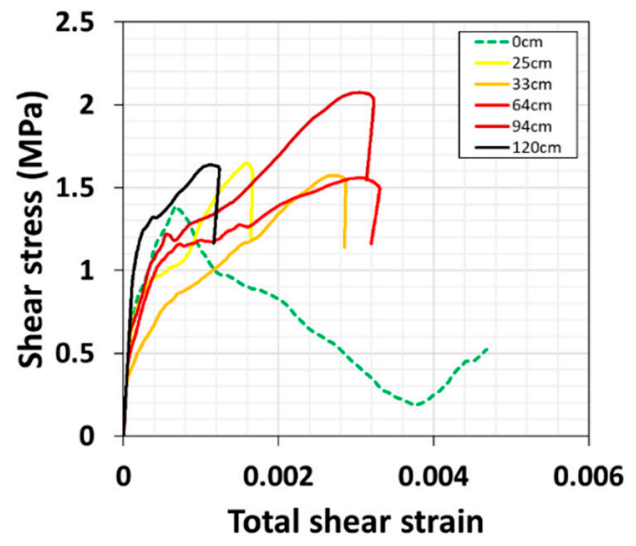

(a)

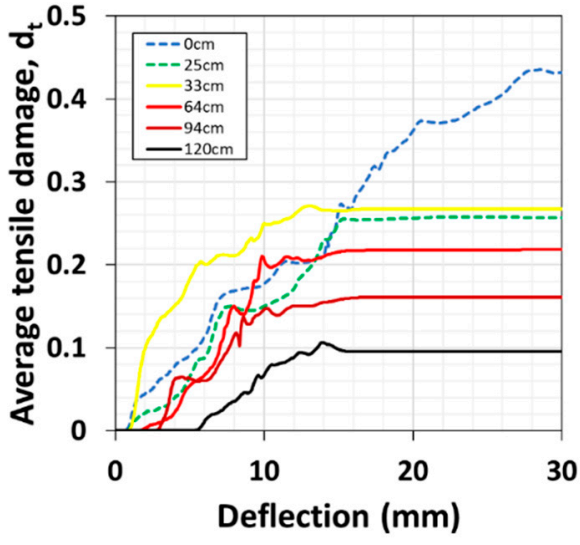

(b)

Figure 11. (a) Shear stress-strain plots, and (b) Tensile damage index-deflection plots at the various monitoring lines $(0,250,330,640,940$, and $1200 \mathrm{~mm})$.

Mihaylov et al. [16,17] defined a critical loading zone under the loading plate, which creates the tip of the shear crack. This was viewed as a rigid block; the "whole truss analogy" was used to model the bottom longitudinal reinforcements and several radial compression struts (Figure 12a). Axial deformation of the bottom longitudinal reinforcements causes a radial rigid strut to rotate around the loading platten, widens the inclined crack, and triggers slippage on the crack surface. The two kinematic compatibility conditions are the vertical displacement $\Delta_{c}$ under the loading platten and the average strain $\varepsilon_{t, a v g}$ of the bottom longitudinal reinforcements (i.e., the displacement field between the two overall shears). The first term represents the behavior of elastic-fixed dowels subjected to a relative transverse support displacement $\Delta_{c}$. The second term reflects the formation of plastic hinges at the ends of the dowels; the moment capacities of the hinges are reduced by the tension force $\mathrm{T}$ acting on the bars. The variable $l_{t}$ is the length of the bottom reinforcement within the cracked part of the shear span, as illustrated in the free-body diagram of Figure 12a. 


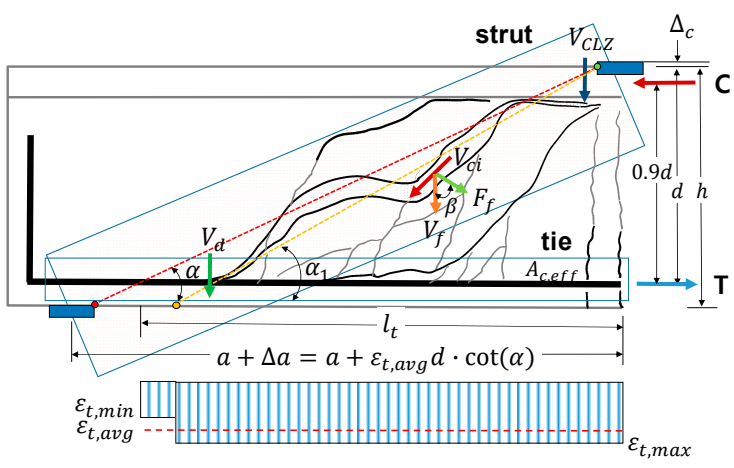

(a)

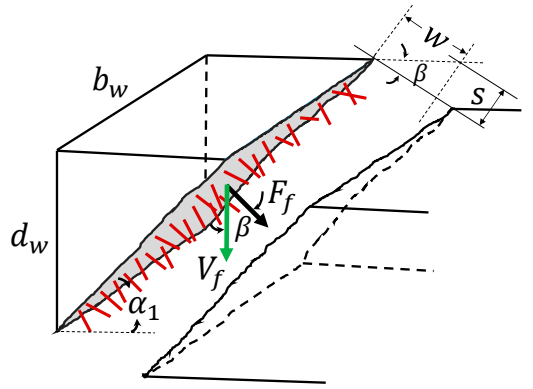

(b)

Figure 12. The principal assumptions of the kinematic model (with two degrees of freedom) and variation of the angle $\alpha_{1}$ during transition from deep to slender beams. (a) Redrawn and modified from Mihaylov et al. (2013). (b) The relationships among the SF force, the SF-induced shear force, and the angle $\beta$.

The shear resistance of SFRC in a beam without shear reinforcement is given by Equation (1). Because that the shear force can be expressed in two ways, the equilibrium of the spring forces requires the following arrangement:

$$
R\left(\varepsilon_{t, a v g}, \Delta_{c}, \alpha\right)=V_{\text {equilibrium }}-V_{\text {kinematics }}=\frac{T(0.9 d)}{a}-\sum V_{n}=0
$$

where $R$ is the residual function in terms of the two kinematic dofs, $\Delta_{c}, \varepsilon_{t, a v g}$, and $\alpha$. This residual equation was iteratively minimized by using bi-section method. The first term of Equation (1) for the force $\mathrm{T}$ is the yield force of the bottom longitudinal reinforcement:

$$
\mathrm{T}=E_{s} A_{s} \varepsilon_{t, a v g}+\frac{0.33 \sqrt{f_{c k}}}{1+\sqrt{200 \varepsilon_{t, a v g}}} A_{c, e f f} \leq A_{s} f_{y,} A_{c, e f f}=\min \left[2.5(h-d), \frac{h}{2}\right] b
$$

where the first term considers the resistance of the bare steel reinforcement. The second term describes concrete tension stiffening. $\sum V_{n}$ is consist of $V_{c l z}, V_{c i}, V_{d}$, and $V_{f}$. These are the shear resistances of the critical load region, the aggregate interlock with shear cracks (contact density model; Li et al. [37]), the dowels of the bottom longitudinal reinforcement, and the shear resistance imparted by the SFs respectively $[16,17]$. The sum of these forces must balance the force defined as the sectional resistance moment generated by the tensile force $\mathrm{T}$ when the internal moment arm length is approximately $0.9 \mathrm{~d}$. A simplified divergence model (Lee et al. [25], Voo et al. [38]) was used to calculate the additional tensile stress $F_{f}$ that would occur if the SFs were to crack (i.e., the stress transferred from the concrete matrix to the crack).

Figure 13 shows the shear capacities (yielded by various analyses) and the experimental results. The shear capacity of the T-beam was approximately $350 \mathrm{kN}$. The nonlinear analyses of ABAQUS [28], Vector2 [35], Vector3 [39], and ATENA [40] were in good agreement with the experimental data. However, the strains at the level of the longitudinal reinforcing bar differed according to the chosen platform and model (i.e., the continuum-damage, fracture energy-based inelasticity, and modified MCFT models). The continuum-damage model yielded good strain data at the level of the bottom reinforcement. The shear capacity calculated using the two-kinematic strut-tie model established by Mihaylov et al. (2013, $2015,2017)$ was also reliable. Because that model was originally developed for deep beams $(\mathrm{a} / \mathrm{d}<2.5)$, its $\varepsilon_{t, a v g}$ was stiffer than the $\varepsilon_{t, a v g}$ of our T-beam $(\mathrm{a} / \mathrm{d}=2.9)$. Our T-beam was slender; the $\varepsilon_{t, a v g}$ was approximately two-fold greater than the $\varepsilon_{t, a v g}$ of the strut-tie model. Furthermore, the crack inclination angle $\alpha_{1}$ averaged $21^{\circ}$, which was less than the $35^{\circ}$ of previous works. The differences reflect the shear span variations between slender and deep beams. 


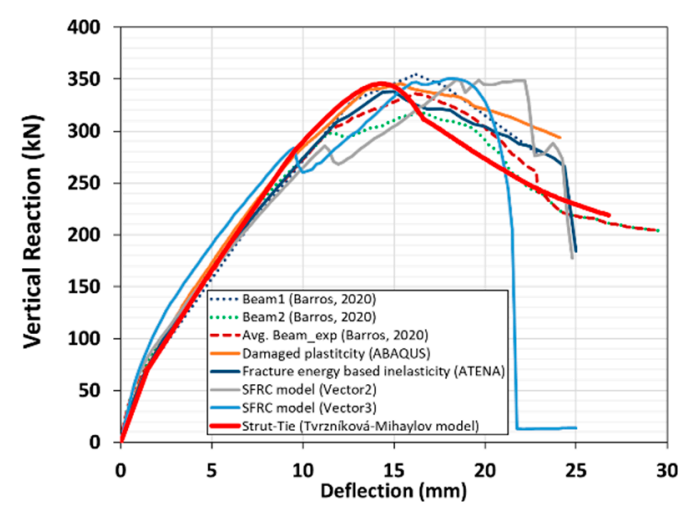

(a)

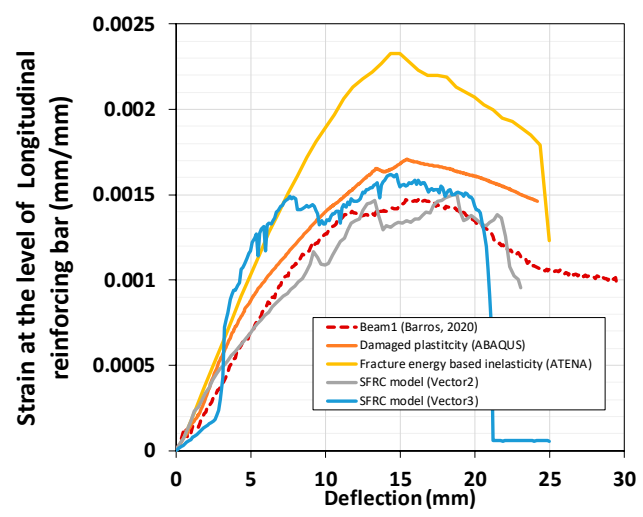

(b)

Figure 13. Shear capacities: (a) Load-deflection curve. (b) Strain curve at the level of the bottom reinforcement.

\section{Conclusions}

Nonlinear failure analysis of an SFRC T-beam was performed and compared with experimental data in order to look at the possibility to replace conventional shear reinforcements with SFs. The shear capacities yielded by various analyses were compared with the experimental results. Three $360 \times 360 \mathrm{~mm}$ web elements between the shear span were selected, then traced the changes in the principal axis caused by crack development and propagation. The changes in the crack angle according to the average strain of the bottom longitudinal reinforcement and the vertical strain of the web element were monitored. For verification, the strut-tie model to predict shear capacity was selected.

- The shear capacity of the T-beam was approximately $350 \mathrm{kN}$. The nonlinear analyses of ABAQUS, Vector2, Vector3, and ATENA were in good agreement with the experimental results.

- However, the strains at the level of longitudinal reinforcing differed according to the chosen platform and the model (the continuum-damage, fracture energy-based inelasticity, and modified MCFT models). The continuum-damage model accurately predicted strain at the level of the bottom reinforcement.

- In the case of Vector2/MCFT, which is based on strain, the progressive failure of web elements is well depicted in the biaxial strain relationship. Conversely, ABAQUS result shows better failure trace of web elements under their biaxial stress state in a stress-based Mohr circle. MCFT, which analyzes changes in macro-web elements based on average strain and average stress, can be interpreted as more suitable for SFRC structures than relatively local nodal or element-based analysis. While the ABAQUS result shows better force-displacement excursion curve up to the failure. In addition, the damaged plasticity model reproduces more realistic crack patterns.

- The shear capacity yielded by the two-kinematic strut-tie model established by Mihaylov et al. was in good agreement with the experimental data. Because that model was originally developed for deep beams $(\mathrm{a} / \mathrm{d}<2.5)$, it estimates $\varepsilon_{t, a v g}$ stiffer than that of the T-beam $(\mathrm{a} / \mathrm{d}=2.9)$. Since the T-beam was slender, the $\varepsilon_{t, a v g}$ was approximately two-fold greater than the $\varepsilon_{t, \text { avg }}$ of the strut-tie model. Furthermore, the crack inclination angle $\alpha_{1}$ averaged $21^{\circ}$, which was less than the $35^{\circ}$ of previous works (Mihaylov et al., 2013). The differences reflect the shear span variations between slender and deep beams.

Funding: This research was supported by the National Research Fund of Korea (grant no. NRF2021R1A2C1004567) and the Ministry of Trade, Industry and Energy (MOTIE) of Korea (grant no. 20193110100020).

Institutional Review Board Statement: Not applicable. 
Informed Consent Statement: Not applicable.

Data Availability Statement: Data-sharing is not applicable here.

Acknowledgments: This paper is dedicated to Woo Kim on the occasion of his 70th birthday.

Conflicts of Interest: The author declares no conflict of interest.

\section{References}

1. Popovics, S. A Review of Stress -Strain Relationships for Concrete. ACI J. 1970, 67, 243-248.

2. ACI-ASCE Task Committee 426. The shear strength of reinforced concrete members. Proc. ASCE 1973, 99, 1091-1187.

3. ACI-ASCE Committee 445. Recent approaches to shear design of structural concrete. J. Struct. Eng. ASCE 1998, $124,1357-1417$.

4. Vecchio, F.J.; Collins, M.P. The Modified Compression-Field Theory for Reinforced Concrete Elements Subjected to Shear. ACI Struct. J. 1986, 83, 219-231.

5. Hsu, T.T.C.; Mo, Y.L. Unified Theory of Concrete Structures; John Wiley \& Sons Ltd.: West Susex, UK, 2010.

6. $\quad$ fib. MC2010: 5.6 Fibres/Fibre-Reinforced Concrete; CEB·FIP: Lausanne, Switzerland, 2010; pp. 220-231.

7. $\quad$ Kim, W. Limit State Design for Concrete Structures (Written in Korean); Dongwha Tech. Pub.: Seoul, Korea, 2015 ; p. 692.

8. Bentz, E.C.; Vecchio, F.J.; Collins, M.P. Simplified modified compression field theory for calculating shear strength of reinforced concrete elements. ACI Struct. J. 2006, 103, 614-624.

9. Slater, E.; Moni, M.; Alam, M.S. Predicting the shear strength of steel fiber reinforced concrete beams. Constr. Build. Mater. 2012, 26, 423-436. [CrossRef]

10. Zhang, F.; Ding, Y.; Xu, J.; Zhang, Y.; Zhu, W.; Shi, Y. Shear strength prediction for steel fiber reinforced concrete beams without stirrups. Eng. Str. 2016, 127, 101-116. [CrossRef]

11. Cheng, K.; Zhang, J.; Dai, Q.L.; Wang, P.Y.; Zhang, J. Shear Performance of Steel Fiber Reinforced Concrete Beams Without Stirrups: Experimental Investigation. Int. J. Civ. Eng. 2020, 18, 865-881.

12. Yuan, T.F.; Yoo, D.Y.; Yang, J.M.; Yoon, Y.-S. Shear Capacity Contribution of Steel Fiber Reinforced High-Strength Concrete Compared with and without Stirrup. Int. J. Concr. Struct. Mater. 2020, 14, 1-15. [CrossRef]

13. Barros, J.A.O.; Figueiras, J.A. Flexural behavior of SFRC: Testing and modeling. ASCE J. Mater. Civ. Eng. 1999, 11, 331-339. [CrossRef]

14. Kwak, Y.-K.; Eberhard, M.O.; Kim, W.-S.; Kim, J. Shear strength of steel fiber-reinforced concrete beams without stirrups. ACI Structural J. 2002, 99, 530-538.

15. Abad, B.F.; Lantsoght, E.; Yang, Y. Shear capacity of steel fibre-reinforced concrete beams. In CONCRETE Innovations in Materials, Design and Structures: Proceedings of the fib Symposium 2019 held in Krakow, Poland 27-29 May 2019; Derkowski, W., Krajewski, P., Gwozdziewicz, P., Pantak, M., Hojdys, L., Eds.; International Federation for Structural Concrete: Krakow, Poland, 2019; pp. 1710-1717.

16. Mihaylov, B.I.; Bentz, E.C.; Collins, M.P. Two-parameter kinematic theory for shear behavior of deep beams. Int. J. Cem. Compos. Lightweight Concr. 2010, 6, 263-271.

17. Mihaylov, B.I.; Bentz, E.C.; Collins, M.P. Two-parameter kinematic theory for shear behavior of deep beams. ACI Structural J. 2013, 110, 447-455.

18. Calvi, P.M. A Theory for the Shear Behaviour of Cracks Providing a Basis for the Assessment of Cracked Reinforced Concrete Structures. Ph.D. Thesis, University of Toronto, Toronto, ON, Canada, 2015; p. 367.

19. Lobet, R. Modelling of the Shear Behaviour of Coupling Beams with Fibre-Reinforced Concrete. Master Thesis, University of Liège, Liège, Belgium, 2017; p. 110.

20. Tvrznikova, K. Two-Parameter Kinematic Approach for the Shear Behavior of Deep Beams Made of Fiber-Reinforced Concrete. Master's Thesis, University of Liège, Liège, Belgium, 2017; p. 100.

21. Mihaylov, B.I. Five-spring model for complete shear behavior of deep beams. Struct. Concr. 2015, 16, 71-83. [CrossRef]

22. Mihaylov, B.I.; Hunt, B.; Bentz, E.C.; Collins, M.P. Three-parameter kinematic theory for shear behavior of continuous deep beams. ACI Structural J. 2015, 112, 47-57. [CrossRef]

23. Mihaylov, B.I.; Hannewald, P.; Beyer, K. Three-parameter kinematic theory for shear-dominated reinforced concrete walls. ASCE J. Struct. Eng. 2016, 142, 1-14. [CrossRef]

24. Mansur, M.A.; Ong, K.C.G. Behavior of Reinforced Fiber Concrete Deep Beams in Shear. ACI J. 1991, 88, 98-105.

25. Lee, S.-C.; Cho, J.-Y.; Vecchio, F.J. Simplified Diverse Embedment Model for Steel Fiber-Reinforced Concrete in Tension. ACI Structural J. 2013, 110, 403-412.

26. Lee, S.-C.; Cho, J.-Y.; Vecchio, F.J. Tension-stiffening model for steel fiber-reinforced concrete containing conventional reinforcement. ACI Structural J. 2013, 110, 639-648.

27. Barros, J.; Sanz, B.; Kabele, P.; Yu, P.K.; Meschke, G.; Planas, J.; Cunha, V.; Caggiano, A.; Ozyurt, N.; Gouveia, V.; et al. Blind Competition on the Numerical Simulation of Steel-Fiber-Reinforced Concrete Beams failing in Shear. Struct. Concrete 2021, 22, 939-967. [CrossRef]

28. Smith, M. ABAQUS/Standard User's Manual; Dassault Systèmes Simulia Corp.: Providence, RI, USA, 2020.

29. Lubliner, J.; Oliver, J.; Oller, S.; Onate, E. A plastic-damage model for concrete. Int. J. Soilds Struct. 1989, 25, 299-326. [CrossRef] 
30. Lee, J.; Fenves, G.L. A plastic-damage model for cyclic loading of concrete structures. J. Eng. Mech. ASCE 1998, 124, 892-900. [CrossRef]

31. Hashim, D.T.; Hejazi, F.; Lei, V.Y. Simplified Constitutive and Damage Plasticity Models for UHPFRC with Different Types of Fiber. Int. J. Concr. Struct. Mater. 2020, 14, 1-21. [CrossRef]

32. Minh, H.-L.; Khatir, S.; Wahab, M.A.; Cuong-Le, T. A concrete damage plasticity model for predicting the effects of compressive high-strength concrete under static and dynamic loads. J. Build. Eng. 2021, 44, 1-13.

33. Ombres, L.; Verre, S. Shear strengthening of reinforced concrete beams with SRG (Steel Reinforced Grout) composites: Experimental investigation and modelling. J. Build. Eng. 2021, 42, 1-17. [CrossRef]

34. Bai, W.; Lu, X.; Guan, J.; Huang, S.; Yuan, C.; Xu, C. Stress-Strain Behavior of FRC in Uniaxial Tension Based on Mesoscopic Damage Model. Crystals 2021, 11, 689. [CrossRef]

35. Wong, P.S.; Vecchio, F.J.; Trommels, H. Vector 2 E FormWorks User's Manual, 2nd ed.; Vectoranalysis.com: Toronto, ON, Canada, 2013; p. 347.

36. Eligehausen, R.; Popov, E.; Bertero, V. Local Bond Stress-Slip Relationship of Deformed Bars under Generalized Excitations; Report No. UCB/EERC-83/23; Earthquake Engineering Center, University of California: Berkeley, CA, USA, 1983; pp. 69-80.

37. ElMohandes, F.; Vecchio, F.J. Vector3 User's Manual, 2nd ed.; Vectoranalysis: Toronto, ON, Canada, 2013 ; p. 153.

38. Li, B.; Maekawa, K. Contact density model for cracks in concrete. In Proceedings of the IABSE Colloquium DELFT 1987: Computational Mechanics of Concrete Structures-Advances and Application, Delft, The Netherlands, 26-28 August 1987; Volume 54, pp. 51-62.

39. Voo, J.Y.L.; Foster, S.J. Variable Engagement Model for Fiber-Reinforced Concrete in Tension; Uniciv Report No. R-420; University of New South Wales: Sydney, Australia, 2003; p. 86.

40. ATENA, Program document ATENA 3D Tutorial \& Manual; Červenka Consulting: Prague, Czech Republic, 2013 ; p. 120. 